Türkiyat Mecmuası, C. 25/Güz, 2015, s. 347-357

\title{
ESKİ UYGURCA BİR CÜMLE ÜZERINE BAZI DÜŞÜNCELER
}

\section{Mehmet Mahur TULUM*}

\begin{abstract}
ÖZ
İlk neşrinden bu yana yüz yılı aşkın bir zaman geçmiş olan "KalyanamkaraPapamkara" yazması üzerine birçok çalışma yapılmış, çeşitli problemleri için farklı teklifler ileri sürülmüştür. Buna rağmen yazmanın muhtelif kısımları günümüze kadar çözülememişs sorunları barındırmaktadır. Bu sorunlardan birisi de yazmada yer alan eksik bir cümledir ve bizce bugün hâlâ açığa kavuşturulamamıştır. Yazmada yer alan bu cümledeki iki ifade farklı okuma ve anlamlandırma teklifleriyle açıklanmaya çalışılmış, fakat bunlar söz konusu cümlenin anlaşılması için doyurucu olamamıştır. Bu kısmın doğru anlaşılması metnin bütünlüğü için de önem arz eder. $\mathrm{Bu}$ çalışmada daha önce bu eksik cümle üzerine öne sürülen tekliflere yer verilecek, ardından da bu teklifler üzerine bazı düşünceler ileri sürülecektir. İlk problemli mesele, birtakım etimolojik açıklamalardan sonra tarihî ve modern Türk lehçelerinden verilen örneklerle desteklenecektir. İkinci problemli mesele ise, bizzat yazmanın kendisinden hareketle değerlendirilecektir. Gerekli görülen noktalarda yazmanın fotoğraflarına da yer verilmiştir. Söz konusu iki yapı açıklandıktan sonra, cümle için yeni bir transliterasyon, transkripsiyon ve Türkiye Türkçesi çevirisi teklif edilecektir.
\end{abstract}

Anahtar Kelimeler: Eski Türkçe, Eski Uygurca, Kalyanamkara-Papamkara, Avadan.

\footnotetext{
* Doç. Dr., Anadolu Üniversitesi, Edebiyat Fakültesi, Türk Dili ve Edebiyatı Bölümü,
} mmtulum@anadolu.edu.tr 


\title{
SOME THOUGHTS ON AN OLD UIGHUR SENTENCE
}

\begin{abstract}
Many studies have been conducted on Kalyanamkara-Papamkara manuscript which more than hundred years have passed over its first publication and different proposals are suggested to its different sections. Despite this various sections of the manuscript contains the problems which couldn't have been solved until today. One of these problems is the elliptical sentence contained in the manuscript. Basically the two important structures contained in the manuscript are tried to be explained by means of different reading and interpretations but they couldn't have been sufficient to understand the said sentence. Thus, it prevented understanding of the whole of text. In this study, the assertions made on the elliptical sentence will be given place and then ideas about these assertions will be set forth. The first problematical structure will be tried to be explained by giving places to the examples from historical and modern Turkish dialects. The second problematic structure will be examined by dealing as manuscript centred entirely. The photos of the manuscript will be given place required for all these. Lastly, after the two structures explained, a new transliteration, transcription and translation in to Turkey Turkish of the said sentence will be offered.
\end{abstract}

Keywords: Old Turkish, Old Uigur, Kalyanamkara Papamkara, Avadan. 
Bibliothèque Nationale (Fransa Milli Kütüphanesi)'nde Pelliot Chinois 3509 numarasıyla kayıtlı olan ve genel kabul gören adiyla "Kalyanamkara-Papamkara" yazması Eski Uygur Türkçesi edebî mahsulleri arasında oldukça mühim bir eserdir. Eser XX. yüzyılın ilk çeyreğinde DunHuang mağaralarında Paul Pelliot tarafından bulunmuş ve söz konusu kütüphaneye teslim edilmiştir. $\mathrm{Bu}$ tarihten itibaren birçok araştırmacı tarafından incelenen yazmada, hâlen açıklığa kavuşturulamamış birçok problemli yer vardır.

Söz konusu problemli yerlerden olduğu görülen, altıncı sayfanın sonunda eksik bir cümle içinde yer alan ve bugüne kadar araştırmacılar

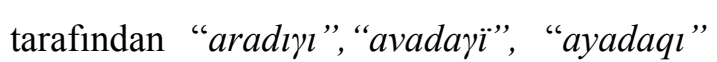

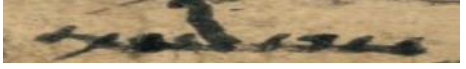
olarak okunan kelime ile "yinču-i munçuq", "yinčü-i(?) munçuү”, “yençü 2 monçuq" as 2 ses 5 biçimlerinde okunmuş olan söz öbeğine karşıllk yeni bir okuma ve anlamlandırma teklifi ileri sürülerek bu metin yeniden kurulacaktır. ${ }^{1}$ Cümlenin yüksek çözünürlüklü fotoğrafi aşağıdadır: ${ }^{2}$

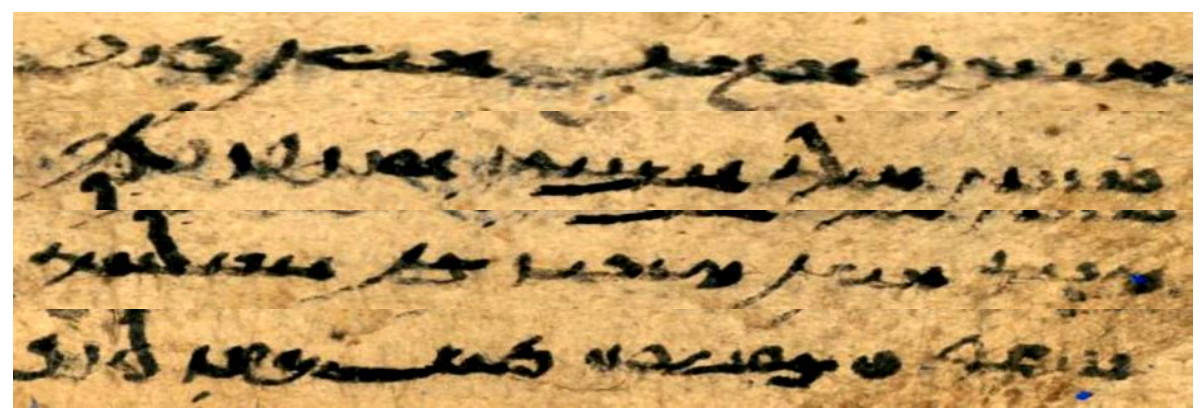

\footnotetext{
12015 yılında metnin rekonstrüksiyonunu ortaya koyarken kendime ait okumalarım olarak şu tez çalışmasında da öne sürülmüştür: K. Azıll; "Eski Uygurca İyi Niyetli Hanzade İle Kötü Niyetli Hanzade Metninin Rekonstrüksiyonu", Danışman: Mehmet Mahur Tulum, Anadolu Üniversitesi Sosyal Bilimler Enstitüsü Türk Dili ve Edebiyatı Bölümü, Yayınlanmamış Yüksek Lisans Tezi, Eskişehir, 2015. Değerli öğrencim Kenan Azılı'nın tamamen kendisine ait olan isabetli yeni okuma teklifleri önümüzdeki süreçte makaleler hâlinde yayımlanacaktır. ${ }^{2} \mathrm{http} / /$ gallica.bnf.fr/ark:/12148/btv1b8300799c.r=pelliot+chinois+3509.langEN (Erişim tarihi: 03.03.2014)
} 
Anılan yazma üzerinde ilk çalışmayı yapan Clement Huart yukarıdaki cümleyi şu şekilde transkribe edip çevirir: ${ }^{3}$

Qangi ilig inčä tip irliq-qadi: Amraq ögögüm, s[äni] inčä sävär mn. Aradıүl yinču-i munçuq-täg köz-dä-ki.

Son père, le roi, rèpondit: mon cher fils, voici comment je t'aime. La perle qu'il avait cherchèe, dans l'oeil semblable à un joyau

"Sevgili oğlum, Kral, cevapladı: 'Seni nasıl sevdiğim ortada. Aradığı inci, bir mücevher gibi gözün içinde (duruyor)."

Huart, makaleye konu olan bu cümle içindeki sorunlu ilk kelimeyi "aradırı" şeklinde okuyup Fransızca'ya "avait cherchèe=aradığı" olarak çevirmiş, dolayısıyla kelimeyi yanlış bir gramer çözümlemesiyle "ara-" fiiliyle ilişkilendirmiştir. Diğer problemli söz öbeğini de kelimeler arasında açıkça yazıldığı görülen /y/ harfinden dolayı, "yinču-i munçuq" biçiminde okumuştur.

Huart'ın çalışmasını beğenmeyip yazmayı tekrar ele alan Pelliot ise, bu cümleyi şu şekilde transkribe edip çevirmiştir: ${ }^{4}$

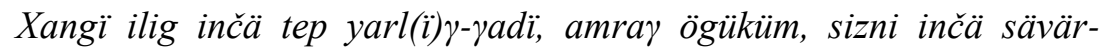

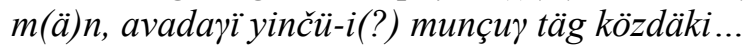

Le roi son père parla ainsi: mon cher enfant, voici comme je vous aime, et...des perles,...comme des pierres precieuses.

"Babası Kral arz ettiler: 'Sizi şöyle seviyorum,...ve... inciler,... değerli taşlar gibi."

Pelliot cümledeki sorunlu ilk kelimeyi "avadayï" şeklinde okumasına rağmen çevirisinde göz ardı etmiştir. Cümledeki sorunlu ikinci kısmı Huart gibi "yinčü-i munçuy" şeklinde okuyan Pelliot, bir sıkıntı olduğunu fark edip yanına soru işareti koymuş, verdiği dipnotta da bu ifadede bir belirsizlik olduğunu, "avadayī" kelimesini anlamlandıramadığını ve "yinčü-i"nin ise izah edilemeyeceğini itiraf etmiştir. Bununla birlikte, Huart'ın okuyuşunun da kabul edilemez olduğunu kaydeder.

\footnotetext{
${ }^{3}$ C. Huart; "Le Conte Bouddhique Des Deux Freres En Langue Turque Et En Caracteres Ouigours", Journal Asiatique, 1914, C.3, No: 11, s.12.

${ }^{4}$ P. Pelliot; "La Version Ouigoure De L'histoire Des Princes Kalyânamkara Et Pâpamkara", Toung Pao, 1914, XV, s. 233.
} 
Hüseyin Namık Orkun, Pelliot'un okumalarını Türkiye'de "satır arası anlamlandırma" şeklinde yeniden yayımlamış, fakat aynı yanlışları devam ettirmiştir. $^{5}$

Eserin bugüne kadarki en kapsamlı ve ayrıntılı yayınını yapan James Russell Hamilton ${ }^{6}$, metni şu şekilde seslendirir:

qayı ellig inçä tep yarlig-qadı amraq ögüküm seni inçä sevär men ayadaqı yençü 2 monçuq täg közdäki...

Türkiye'de yayımlanan eserlerde ${ }^{7}$ Fransızca aslından Türkiye Türkçesine çevirisi şöyle yer alır:

Babası Kral: "Sevgili yavrucuğum, seni işte şöyle: avcumun içindeki inci 2 boncuk gibi, gözlerdeki... seviyorum" diye cevap verdi.

Hamilton, çalışmasının sonundaki notlar kısmında sorunlu ilk kelimeyle ilgili olmak üzere yaptığı açıklamada daha önceki okuyuşlara katılmayıp, üçüncü harfin /y/den çok /v/yi andırsa da kesinlikle ayadaqı okuyuşunun daha doğru olacağını iddia eder. Bunu da Çin kültüründe sevilen bir çocuğun avuçtaki inciye benzetilmesine dayandırır. İkinci problemli yapıyı ise, yençü 2 monçuq olarak transkribe eder. Hamilton burada diğer okuyuşların yanlış olduğunu ileri sürerek ilgili notunda Soğd harfli metinlerdeki rakamların yazılışlarını delil gösterip burada birbirine bağlı iki küçük çizgi olduğunu ve bunun da 2 rakamına karşıllk geldiğini söyler. Sonra da kendini alamayarak "gözdeki" ile "avuçtaki iki inci tanesi" arasında herhalde var olması gereken ilişkiyi göremiyorum" tuhaf açıklamasında bulunur. Türkiye'deki yayınların giriş kısmına konulan düzeltmelerin içinde Semih Tezcan'a ait bir düzeltme teklifi de bu konuyla ilgilidir. Tezcan ikinci kısımda sadece bir yazım hatası olduğunu düşünmektedir. ${ }^{8}$

\footnotetext{
${ }^{5}$ H. N. Orkun; Prens Kalyanamkara ve Papamkara Hikâyesinin Uygurcası, TDK Yayınları, İstanbul, 1940, s. 21.

${ }^{6}$ J. R. Hamilton; Manuscripts Ouigours De Touen- Houang: Le Conte Bouddhique Du Bon Et Du Mauvais Prince En Version Ouigoure, Klincksieck, Paris, 1971.

${ }^{7} \mathrm{Bu}$ yayınlar şunlardır:

J. R. Hamilton; Budacı Iyi ve Kötü Kalpli Prens Masalının Uygurcası (çev.: Ece Korkut-İsmet Birkan, Yayımlayan: Mehmet Ölmez), Simurg Yayınları, Ankara, 1998.

J. R. Hamilton; Iyi ve Kötü Kalpli Prens Öyküsü (çev.: Vedat Köken), TDK Yayınları, Ankara, 1998.

${ }^{8}$ S. Tezcan; "James Russell HAMILTON: Le Conte Bouddhique Du Bon Et Du Mauvais Prince En Version Ouigoure Mission Paul Pelliot Documents Conserves A La Bibliotheque
} 
Daha sonra Türkiye'de yapılan tez ve diğer çeşitli çalışmalarda da Hamilton'un izahı -doğru kabul edilmiş olmalı ki- tekrar tekrar bu biçimiyle yer almıştır. Burada bu çalışmalara yer verilmeyecektir.

Bütün bunlardan sonra, cümledeki birinci problemli kelimenin ' $V$ 'DNXY avad[a]nqı olarak okunmasını teklif ediyoruz. Öncelikle, Uygur imlâsında /a/ ve /n/ harfleri birbirlerine oldukça benzer. /d/ harfinden sonra gelen harf bugüne kadar israrla sadece /a/ okunmuştur. Ancak bu harfi /n/ olarak okumak hiç de zorlama olmaz. Zira Uygur imlâsında ünlülerin çoğu kez yazılmadığı da bilinir. O hâlde, kelimenin bir başka alternatif olarak avad [a]nqı şeklinde okunması mümkün gözükür.

Bu noktada, her ne kadar konunun merkezi dışında kalsa da avadan kelimesinin yapısını açıklamaya çalışmak yararlı olacaktır. Öncelikle, Farsça $\hat{a} b$ kelimesinden hareket edilmelidir. Buna istinaden Soğdca'ya inildiğinde şunlar tespit edilir:

'p āp ('ph) $\rightarrow$ 'b, 'p water (s.8/1); '’pkyn āpkēn crystal (s.8/2);

'pkyn'k āpkēnē ('pkyny(y)) <* āpaka (of) crystal (s.8/2);

"pkynch āpkēnč f. adj. (of) crystal (s. 9/1); ßjyr'ēnč f. adj.

əßžyr ‘̄ēč (made of) diamond (s. 18/2)

Yukarıdaki etimolojik izahlarda görüldüğü gibi feminen "āp(a)" kelimesinin daha o dönemlerde "su" anlamının yanında "kristal; elmas" gibi değerli taşları da karşıladığ 1 tespit edilir. Bu anlam gelişmesinin daha sonraki dönemlerde de devam ettiği izlenir. Şöyle ki, Meninski'nin sözlüğünde "âb" kelimesinin anlamı için verilen karş1lılardan birisi "cevher"dir. ${ }^{10}$ Yine Steingass sözlüğünde "âb" kelimesi için "pearl, jewel, gem"" yani "inci, mücevher, kıymetli taş" anlamları verilir. Dolayısıyla yukarıdaki izahı doğrular nitelikte mecaza dayalı bir anlam alanı şu şekilde takip edilir:

âp(a) $\rightarrow$ kristal/elmas $\rightarrow$ inci $\rightarrow$ değerli taş/mücevherat

\footnotetext{
Nationale III Manuscrits Oigours De Tounen-Houang. Editions Klincksieck Paris 1971. 204 s. (163-204. sayfalar tipkıbasim)", TDAY-B 1977, s. 241.

${ }^{9}$ G., Badrozzamân, Sogdian Dictionary, Sogdian-Persian-English, Farhangan Publications, Tehran, 1995.

${ }^{10}$ M. Tulum; 17. Yüzyıl Türkçesi ve Söz Varlı̆̆g, TDK Yayınları, Ankara, 2011, s. 243.

11 F. Steingass; A Comprehensive Persian-English Dictionary, Çağrı Yayınları, İstanbul, 2005, s. 1/I.
} 
Kelimenin ikinci kısmındaki "-dân” eki için ise şunlar kaydedilebilir. Steingass, -dân ekinin işlevini "(eklendiği tabanın ifade ettiği kavramı) "barındıran", "tutan" (anlamlı isimler hâline getirmek)" olarak tanımlar. ${ }^{12} \mathrm{Bu}$ sonekin Eski Farsça birleşik isimler yapan "-dâna" kelimesinden Orta ve Yeni Farsça'ya küçük bir ses değişikliğiyle geçerek ekleştiği ve eklendiği isimleri alet ismi yapmaya yaradığ 1 görülür. Bu iddia, daivadāna kelimesi için yapılmış şu açıklamalarla desteklenir:

"daivadāna eski Farsça bir terim olarak "Tanrılar Tapınağı" anlamına gelir ve eski Parsa antik kentinde I. Serhas (M. Ö. 486-65) adına yapılan “Daiva Yazıtı'nda " geçer. pasāva vašnā Auramazdāha adam avam daivadānam viyakanam "Daha sonra, Ahura-mazdā uğruna, Tanrılar Tapınağını yıktım." Birleşik isim Gershevitch'in belirttiği gibi daiva "tanrı" ve dāna- (< *dmHno-) "bina, ev, yapı" kelimelerinden oluşur. ${ }^{13}$

O hâlde, bugün "gül suyu kabı" anlamına gelen gül-âb-dân (Tü. gülüftan) aslen "içinde gül suyunun durduğu yer/şey" anlamından gelişmiştir. Söz konusu etimolojik açıklamalardan sonra kendi lehçemiz de dahil olmak üzere diğer Türk lehçelerinde avadan kelimesini şu verilerle tanıklamaktayız.

Türkiye Türkçesinde yaşayan -dan ekli örnekler özellikle kap isimleri yapmaktadır. ${ }^{14}$ Çaydanlık örneğinde olduğu gibi aynı fonksiyondaki eklerin üst üste gelmesi de söz konusudur. Öyleyse avadan kelimesi yaşarken aynı zamanda kendi lehçemizde ve diğer Türk lehçelerinde avadanlık örneğine de rast gelinmesi beklenir.

TDK Türkiye Türkçesi Ağızlar Sözlüğü'ne bakıldığında avadan için "1. Kavrulmuş kahvenin soğutulduğu tahta kap. 2. Araç, aygıt. 3. Ziynet eşyası. 4. Av çantası"; avadanlık için "1. Kavrulmuş kahvenin soğutulduğu tahta kap. 2. Araç gereç kutusu. 3. Ziynet eşyası. 4. Alet edevat dolabı, sandığı. 5. Alet edevat yapmak için kullanılacak ağaç" anlamları yer alır.

\footnotetext{
${ }^{12}$ F. Steingass; a.g.e. , s. 500/II

${ }^{13}$ http://www.iranicaonline.org/articles/daivadana-lit “ Zoroaster's Own Contribution, JNES 23, 1964, s. 35.” (Erişim tarihi: 07.08.2015).

${ }^{14}$ M. Tulum; Osmanlı Türkçesine Giriş, Anadolu Üniversitesi Açıköğretim Fakültesi Yayınları, Eskişehir, 2011, s. 258.
} 
Tarihî ve Etimolojik Türkiye Türkçesi Lügati'nde avadanlık "iş takımları, aletler" ${ }^{\prime 15}$ şeklinde tanımlanır. Osmanlı döneminde sefer esnasında takımları, cephane ve tüfekleri taşıyan görevlilerin adının avadan bostancıları ve sarayda sünnet ve sarık odalarıyla bunların sofalarını temizlemek, padişaha ait abdest takımlarını muhafaza etmekle görevli saray hademesinin avadancı olduğu da bilinmektedir. ${ }^{16}$

Gagavuz Türkçesi Sözlüğ̈̈’nde ise; “Avadannık: Enstrüman; envanter. Çiftçilik avadannı: Ziraat alet ve edevatı." karşılıkları görülür. ${ }^{17}$ Kazakça ile Tuvacada yer alan "abdıra" ve "aptara"18 kelimeleri "eşya sandığı" anlamına gelmektedir. Moğolcada aynı anlama gelen karşılıklar ise "abdar" ve "abdarlah"tır. ${ }^{19}$

Bütün bunların 1şı̆̆ında avadan $^{20}$ kelimesi için mecaza dayalı anlam silsilesi şu şekilde tasarlanabilir:

$$
\text { âbdân } \rightarrow \text { su kabı } \rightarrow \text { mücevher kutusu } \rightarrow \text { kutu/sandık } \rightarrow \text { takım çantası }
$$

Cümledeki ikinci sorunlu söz grubu için teklifimiz ise, YYNCW MWNCWX yinçü monçuq okumasıdır. Burada daha önce Huart, Pelliot ve Hamilton'ın okuma tekliflerinin aksine bir istinsah hatası vardır. Dikkatlice bakıldığında müstensih yinçü kelimesini yazdıktan sonra yanlışlıkla aynı kelimeyi tekrar yazmaya başlamış, ancak kelimenin ilk harfini yazdıktan sonra yanlışının farkına vararak durmuş ve biraz boşluk bırakarak sonraki kelime olan monçuk ile devam etmiştir. İşte bu yüzden iki kelime arasında

${ }^{15}$ A. Tietze; Tarihî ve Etimolojik Türkiye Türkçesi Lügati, Simurg Yayınları, İstanbul, 2002, s. 226 .

16 İ. Ayverdi; Misalli Büyük Türkçe Sözlük, Kubbealtı Yayınları, İstanbul, 2006, s. 212/I.

${ }^{17}$ G. A. Gaydarci, E. K. Koltsav.d.;Gagavuz Türkçesinin Sözlüğü (Çev: İsmail Kaynak-A. Mecit Doğru), Kültür Bakanlığı Yayınları, Ankara, 1991, s. 21.

${ }^{18}$ B. Aspandiyarov v.d; Kazak Tiliniๆ Tüsindirme Sözdigi, Kazak SSR Gılım Akademiyasının Baspası, Almatı, 1959, I. cilt, s. 7/II; M. Ölmez, Tuvacanın Sözvarllğı-Eski Türkçe ve Moğolca Denkleriyle, Wiesbaden, 2007, s.76/1.

19 F. D. Lessing; Moğolca-Türkçe Sözlük (Çev: Günay Karaağaç), TDK Yayınları, C.1, Ankara, 2003, s. 6.

${ }^{20}$ Sözlerin Soy Ağacı'nda: “avadanlık=abdanlık< Fa. âbdân su kabı, çanak çömlek, kap kaçak $\rightarrow \mathrm{AB}$, -DAN 'bayındırlık, bayındır yer' anlamına gelen abadanlık ile karıştırılmış olabilir." denilerek iki ayrı kelimenin karıştırılması ile bu anlama ulaşıldığı belirtilir (S. Nişanyan; Sözlerin Soy Ăgacı, Adam Yayınları, İstanbul, 2004, s. 32.). Misalli Büyük Türkçe Sözlük'te de benzer bir karışıklık söz konusudur: "AVADAN i. (Fars. Âbâdân 'mâmur'dan) E.T. Türk ve halk ağzı. Âlet, edevat takımı.” (İ. Ayverdi; Misalli Büyük Türkçe Sözlük, Kubbealtı Yayınları, İstanbul, 2006, s. 212). 
/y/ harfine benzer bir şekil kalmıştır. Müstensih tarafindan çizilerek veya karalanarak iptal edilmeyen bu yazım hatası araştırmacıları şüpheye sevk etmiştir.

Cümlede yer alan sorunlu iki yapının buraya kadarki izahlarından sonra cümlenin transliterasyonu şöyle yapılmalıdır:

“ $X$ 'NKY 'YLYK 'YNC' TYP YRLYXX'DY ' MR'X 'WYKWKWM $S Y N Y$ 'YNC' $S$ ' $V$ 'R MN ', $V$ 'DNXY YYNCW MWNCWX T'K $K W Y Z D^{\prime} K Y \ldots$

$\mathrm{Bu}$ okumaya göre transkripsiyonu:

qayı ilig inçe tip y[a]rlıqadı amraq ögüküm sini inçe sever m[e]n avad[a]nqı yinçü monçuq teg közdeki...

olarak ve çevirisi de:

Han babası şöyle buyurdu: "Sevgili yavrum, seni o kadar seviyorum (ki) mücevher kutusundaki inci boncuk gibi, gözdeki..."

şeklinde yapılmalıdır.

Aslında, kaynak dil olan Sanskritçe'deki, Bodisavatlar (Buda adayları)ın Buda olma yolunda sergüzeştlerini anlatan ve Budist öğretiyi telkin eden dinî hikâyelerin içinde toplandığı avadāna kelimesi ile Soğdca menşeli avadan kelimesi arasında etimolojik bir ilgi ${ }^{21}$ nin yanında metaforik bir ilişki de vardır. Soğdca avadan kelimesinin "su kabı" anlamından mecaz yoluyla kazandığı "mücevher kutusu" anlamı aynı zamanda yukarıda açıkladığımız gibi edebî bir tür ismi olan Sanskritçe avadāna kelimesi için de geçerlidir; çünkü bu durumda Bodisavatlar'ın her biri açık istiare yoluyla değerli bir mücevhere benzetilmiştir. ${ }^{22}$

Son olarak, eksik kalan cümleyi konteksti ve semantik paralellikleri gözeterek 101 y1l sonra şu şekilde tamir ederek tamamlamayı teklif ediyoruz:

"közdeki [qaraçuq teg]."

Yani, "gözdeki gözbebeği gibi."

\footnotetext{
${ }^{21}$ K. Röhrborn, Uigurisches Wörterbuch, Lieferung I, Wiesbaden, 1977, s. 278.

${ }^{22}$ Türk edebiyatında antolojiler için "gül-deste" ifadesinin kullanılması da aynı metaforik bağa işaret eder.
} 


\section{KAYNAKÇA}

ASPANDIYAROV, B. v.d.; Kazak Tiliniך Tüsindirme Sözdigi, Kazak SSR G1lım Akademiyasının Baspas1, Almatı, 1959, I. cilt.

AYVERDİ, İlhan; Misalli Büyük Türkçe Sözlük, Kubbealtı Yayınları, İstanbul, 2006, s. 212.

AZILI, Kenan; "Eski Uygurca İyi Niyetli Hanzade İle Kötü Niyetli Hanzade Metninin Rekonstrüksiyonu", Danışman: Mehmet Mahur Tulum, Anadolu Üniversitesi Sosyal Bilimler Enstitüsü, Türk Dili ve Edebiyatı Bölümü, Yüksek Lisans Tezi, Eskişehir, 2015.

BADROZZAMÂN, Gharib, Sogdian Dictionary, Sogdian-Persian-English, Farhangan Publications, Tehran, 1995.

GAYDARCI, G. A., KOLTSA, E. K. v.d.; Gagavuz Türkçesinin Sözlüğü (Çev: İsmail Kaynak-A. Mecit Doğru), Kültür Bakanlığı Yayınları, Ankara, 1991.

HAMILTON, James Russell; Manuscripts Ouigours De Touen- Houang: Le Conte Bouddhique Du Bon Et Du Mauvais Prince En Version Ouigoure, Klincksieck, Paris, 1971.

HAMILTON, James Russell; Budacı Iyi ve Kötü Kalpli Prens Masalının Uygurcası (çev.: Ece Korkut-İsmet Birkan, Yayımlayan: Mehmet Ölmez), Simurg Yayınları, Ankara, 1998.

HAMILTON, James Russell; Lyi ve Kötü Kalpli Prens Öyküsü (çev.: Vedat Köken), TDK Yayınları, Ankara, 1998.

HUART, Clement; "Le Conte Bouddhique Des Deux Freres En Langue Turque Et En Caracteres Ouigours", Journal Asiatique, 1914, C.3, No: 11, s.5-57.

LESSING, F. D.; Moğolca-Türkçe Sözlük (Çev: Günay Karaağaç), TDK Yayınlar1, C.1, Ankara, 2003.

NIŞANYAN, Sevan; Sözlerin Soy Ă̆acı, Adam Yayınları, İstanbul, 2004.

ORKUN, Hüseyin Namı; Prens Kalyanamkara ve Papamkara Hikâyesinin Uygurcası, TDK Yayınları, İstanbul, 1940.

ÖLMEZ, MEHMET, Tuvacanın Sözvarlığı-Eski Türkçe ve Moğolca Denkleriyle, Wiesbaden, 2007, s.76/1. 
PELLIOT, Paul; “La Version Ouigoure De L'histoire Des Princes Kalyânamkara Et Pâpamkara", Toung Pao, 1914, XV, s. 225-272.

RÖHRBORN, Klaus, Uigurisches Wörterbuch, Lieferung I, Wiesbaden, 1977, s. 278.

STEINGASS, F.; A Comprehensive Persian-English Dictionary, Çağr1 Yayınları, İstanbul, 2005.

TEZCAN, Semih; "James Russell HAMILTON: Le Conte Bouddhique Du Bon Et Du Mauvais Prince En Version Ouigoure Mission Paul Pelliot Documents Conserves A La Bibliotheque Nationale III Manuscrits Oigours De Tounen-Houang. Editions Klincksieck Paris 1971. 204 s. (163-204. sayfalar tipkıbasım)", TDAY-B 1977, s. 239-243.

TIETZE, Andreas; Tarihî ve Etimolojik Türkiye Türkçesi Lügati, Simurg Yayinları, İstanbul, 2002.

TULUM, Mertol; 17. Yüzyll Türkçesi ve Söz Varlı̆̆l, TDK Yayınları, Ankara, 2011.

Osmanlı Türkçesine Giriş, Anadolu Üniversitesi Açıöğretim Fakültesi Yayınları, Eskişehir, 2011.

http://gallica.bnf.fr/ark:/12148/btv1b8300799c.r=pelliot+chinois+3509.lang EN (Erişim tarihi: 03.03. 2014)

http://www.iranicaonline.org/articles/daivadana-lit “Zoroaster's Own

Contribution, JNES 23, 1964, s. 35.” (Erişim tarihi: 07.08.2015) 